\title{
FLUTUAÇÃO POPULACIONAL E EFEITO DA DISTÂNCIA E PROFUNDIDADE SOBRE NEMATOIDES EM BANANEIRA NO NORTE DE MINAS GERAIS ${ }^{1}$
}

\author{
REGINACÁSSIAFERREIRA RIBEIRO², FÁBIO RUAS PEREIRAXAVIER ${ }^{3}$, \\ ADELICAAPARECIDA XAVIER ${ }^{4}$, VICENTE FERREIRAALMEIDA $^{5}$, \\ EDSON HYIDU MIZOBUTSI ${ }^{6}$, VICENTE PAULO CAMPOS $^{7}$, \\ SILAMAR FERRAZ ${ }^{8}$, CLAUDIA REGINA DIAS-ARIEIRA $^{9}$
}

RESUMO - Avaliou-se a distribuição de Meloidogyne javanica e Helicotylenchus multicinctus em solo naturalmente infestado, cultivado com banana 'Prata-Anã' irrigada por microaspersão. O ensaio foi conduzido em blocos ao acaso. A população dos fitonematoides foi avaliada nas distâncias de 20; 40; 80 e $120 \mathrm{~cm}$ do pseudocaule e nas profundidades de 20; 40 e $60 \mathrm{~cm}$, bimestralmente, por dois anos. Maior população dos nematoides foi encontrada na profundidade de $20 \mathrm{~cm}$. A população de $M$. javanica e $H$. multicinctus foi maior nas distâncias de 20 e $40 \mathrm{~cm}$, respectivamente. A população tanto de $M$. javanica como H. multicinctus foi elevada em dezembro de 2002 e decresceu até novembro de 2004 quando se estabilizou.

Termos para indexação: Fitonematoides, análise espaço-temporal, Musa.

\section{POPULATION DYNAMICS AND THE EFFECT OF DISTANCE AND DEPTH ON NEMATODES IN BANANA IN THE NORTH OF THE STATE OF MINAS GERAIS, BRAZIL}

\begin{abstract}
The distribution of Meloidogyne javanica and Helicotylenchus multicinctus populations was assessed in naturally infested area cultivated with banana cv. Prata-Anã irrigated by microaspersion. Soil samples were taken at distances of 20,40, 80 and $120 \mathrm{~cm}$ from the pseudostem and from 20,40 and $60 \mathrm{~cm}$ of depth, bimonthly, per two years. The population densities of $M$. javanica and $H$. multicinctus were greater at distances of 20 and $40 \mathrm{~cm}$ from the pseudostem, respectively. The population of both species $M$. javanica and H. multicinctus was high in December 2002 and decreased until November 2004 when it became stable.

Index terms: Musa spp., nematodes, distribution, population dynamic.

\section{INTRODUÇÃO}

A banana é uma das frutas mais consumidas no mundo, sendo explorada na maioria dos países tropicais. O Brasil ocupa o segundo lugar em produção mundial, e Minas Gerais destaca-se como

quinto maior Estado produtor, atrás de São Paulo, Bahia, Pará e Santa Catarina (Agrianual, 2005). No norte de Minas Gerais, atualmente, cerca de 8.000 ha (67\% da área irrigada) são cultivados com banana, predominantemente do Grupo Prata (Portal da Fruticultura, 2007).
\end{abstract}

\footnotetext{
${ }^{1}$ (Trabalho 080-08). Recebido em: 02-04-2008. Aceito para publicação em: 24-08-2008. Financiado pelo CNPq/Apoio: FAPEMIG.

${ }^{2}$ Engenheiro Agrônomo, Dsc., Professora de Educação Superior, Universidade Estadual de Montes Claros. - Rua Reinaldo Viana 2630, 39440-000, Janaúba-MG. Bolsista da Fapemig. regina.ribeiro@unimontes.br

${ }^{3}$ Engenheiro Agrônomo - Instituto Mineiro de Agropecuária, Rua Bueno Brandão, 466, 30120-010, Curvelo-MG, crcv@ima.mg.gov

${ }^{4}$ Engenheiro Agrônomo, Dsc., Professora de Educação Superior, Universidade Estadual de Montes Claros - Rua Reinaldo Viana 2630, 39440-000, Janaúba -MG. adelica@unimontes.br

${ }^{5}$ Biólogo, Msc., Professor de Educação Superior, Universidade Estadual de Montes Claros - Rua Reinaldo Viana 2630, 39440-000, Janaúba - MG. vicente.almeida@unimontes.br

${ }^{6}$ Engenheiro Agrônomo, Dsc., Professor de Educação Superior, Universidade Estadual de Montes Claros, Rua Reinaldo Viana 2630, 39440-000, Janaúba-MG. edson.mizobutsi@unimontes.br

${ }^{7}$ Engenheiro Agrônomo, PhD., Professor Titular, Universidade Federal de Lavras-Departamento de Fitopatologia, 37200000, Lavras - MG. vpcampos@ufla.br

${ }^{8}$ Engenheiro Agrônomo, PhD., Professor Titular, Universidade Federal de Viçosa. Depto de Fitopatologia, 36571-000, Viçosa - MG. silamar@ufv.br

${ }^{9}$ Engenheira Agronoma, Dsc, Professor AdjuntoUniversidade Estadual de Maringá, Umuarama-PR, 87507-190, cdiasariera@bol.com.br
} 
A produtividade média nacional de banana é baixa, cerca de 13,2 t/ha/ano (Agrianual, 2005). Este baixo rendimento deve-se, principalmente, à incidência de fitonematoides (Costa et al., 1997). No Brasil, diversas espécies de nematoides têm sido identificadas associadas às raízes e à rizosfera de bananeira. Os fitonematoides que ocorrem com maior frequência e causam perdas mais expressivas são Radopholus similis, Meloidogyne incognita, Helicotylenchus multicinctus, Pratylenchus coffeae e Rotylenchulus reniformis (Ferraz, 1995; Costa et al., 1997; Gonzaga, 1997). Levantamento realizado por Dias et al. (2001), em bananais de 18 municípios do norte de Minas, mostrou a presença de Meloidogyne spp., Helicotylenchus spp., R. similis, Tylenchus spp., Criconemella spp., Aphelenchoides spp., Pratylenchus spp. e $R$. reniformis. Desses, os mais freqüentes foram Meloidogyne spp, Helicotylenchus spp. e R. similis.

As maiores dificuldades na investigação de fitonematoides em lavouras estão ligadas à natureza dinâmica desses organismos no solo. O sistema ecológico em que vivem os fitonematoides, é uma complexa interação entre a planta hospedeira, o microclima, as propriedades físicas e químicas do solo e os microrganismos (Laughlin \& Lordello, 1977). Daí existirem flutuações populacionais do fitonematoide no tempo e nas direções vertical e horizontal, no perfil do solo. As distribuições vertical e horizontal de alguns nematoides parasitas de plantas têm sido investigadas em diversas culturas, como alfafa, batata, café, cana-de-açúcar, soja, videira, milho e damasco (Tseng et al., 1968; Carneiro et al., 1982; Bird \& Ramsdell, 1985; Almeida et al.,1987; MacGuidwin, 1989; Windham \& Barker, 1993, Davis et al., 1994, Nagy et al., 1998). A bananeira, como uma cultura semiperene, está sujeita, durante todo o ano, ao efeito do ambiente.

No norte de Minas essa cultura tem seu manejo diferenciado, uma vez que sua exploração só é possível devido à prática da irrigação. Nessas condições de manejo, não existem trabalhos mostrando a dinâmica populacional de fitonematoides na cultura da bananeira ao longo do tempo, nem tampouco se conhece como tais parasitas se distribuem no perfil do solo. Assim, o presente trabalho teve por objetivo avaliar o efeito da distância e profundidade sobre a população dos nematoides Meloidogyne javanica e Helicotylenchus multicinctus em solo irrigado cultivado com bananeira 'Prata-Anã' no norte de Minas e a flutuação populacional.

\section{MATERIAL E MÉTODOS}

O experimento foi conduzido em bananal comercial da cultivar 'Prata-Anã' (Musa spp., grupo AAB), implantado no espaçamento $3,5 \times 2,0 \mathrm{~m} \mathrm{e}$ irrigado por microaspersão no município de Janaúba - Minas Gerais. O solo da área foi classificado como franco siltoso (24:45:31, areia:silte:argila) e possuía uma infestação natural de nematoides. Para a instalação do experimento, 50 plantas de bananeira foram selecionadas ao acaso. Destas, cinco plantas constituíram cinco repetições, sendo duas touceiras de bananeira por repetição. Bimestralmente, no período de dezembro/ 2002 a novembro/2004, foram coletadas amostras de solo a quatro distâncias do pseudocaule da planta $(20 ; 40 ; 80$ e $120 \mathrm{~cm})$ e em três diferentes profundidades $(20 ; 40$ e $60 \mathrm{~cm})$ e amostras (100 gramas) de raízes a $30 \mathrm{~cm}$ do pseudocaule, ao redor das plantas. As amostras de solo e raízes foram acondicionadas em sacos plásticos, devidamente identificadas e levadas ao laboratório de Fitopatologia/Nematologia-UNIMONTES para posterior processamento. $\mathrm{O}$ delineamento experimental foi o de blocos ao acaso em esquema fatorial.

Para a extração de nematoides, foram empregados os métodos de Jenkins (1964) e Coolen \& D'Herde (1972), para a extração de nematoides do solo e de raízes, respectivamente. A contagem dos nematoides Meloidogyne e $H$. multicinctus foi realizada em câmara de Peters com auxílio de microscópio estereoscópico. A confirmação da espécie Meloidogyne javanica foi feita a partir de cortes perineais de fêmeas obtidas (Hartman \& Sasser, 1985), presentes nas raízes de bananeira. A identificação de $H$. multicinctus foi feita a partir das características morfológicas (Fortuner, 1991).

Os dados de precipitação, temperatura e umidade relativa, média mensal, foram fornecidos pela Estação Agroclimatológica do Centro Regional de Pesquisa Norte de Minas, de Nova Porteirinha (MG). Para a análise de variância, os dados referentes à população de $M$. javanica nas diferentes profundidades e distâncias foram transformados em $\sqrt{x}$,enquanto para $H$. multicinctus não houve necessidade em função de os dados atenderem às pressuposições básicas da análise de variância. Para verificar a influência da temperatura e da precipitação, foram calculados os coeficientes de correlação " $r$ " com a população de nematoides. 


\section{RESULTADOS E DISCUSSÃO}

Por meio da análise de variância, verificouse que não houve interação significativa entre os fatores profundidade e distância, no entanto houve efeito significativo da profundidade sobre a população dos fitonematoides $(\mathrm{P}<0,05)$. Não houve ajuste de modelos lineares para o número de nematoides, assim as médias foram comparadas pelo teste de Scott-Knott, a 5\%. O número de juvenis de segundo estádio de $M$. javanica foi significativamente superior nas profundidades de 20 e $40 \mathrm{~cm}$, com 40,32 e 36,83\% de ocorrência, respectivamente, quando comparado ao da profundidade de $60 \mathrm{~cm}$, com 22,85\%. Com relação a H. multicinctus, o número de espécimes significativamente superior foi encontrado na profundidade de $20 \mathrm{~cm}$, com 46,98\%, quando comparado ao das profundidades de 40 e $60 \mathrm{~cm}$, com ocorrência de 32,56 e 20,46\%, respectivamente (Tabela 1). Esta maior população dos nematoides na camada de $20 \mathrm{~cm}$ pode ser explicada pela concentração do sistema radicular nos primeiros 20 $\mathrm{cm}$. De acordo com Garcia (2000), cerca de 50\% do número de raízes da bananeira 'Prata-Anã' irrigada por microaspersão em solos arenosos concentramse nos primeiros $20 \mathrm{~cm}$ de profundidade. Araya et al. (1999) verificaram maior população de nematoides (Meloidogyne spp., R. similis, Helicotylenchus spp. e Pratylenchus spp.) em raízes de bananeira Musa AAA cv. Valery) em solo argilo-arenoso, na Costa Rica, aos $30 \mathrm{~cm}$ de profundidade. Já Kashaija et al. (2004), estudando a distribuição vertical de $H$. multicinctus em solo implantado com bananeira (Musa spp. AAA cv. Atwalina), não verificaram diferença significativa entre as profundidades de 0 0,$15 ; 0,15-0,3$ e $0,3-0,5 \mathrm{~m}$. Isto provavelmente ocorreu em função do tipo de solo, que no presente ensaio foi franco-siltoso, enquanto no trabalho de Kashaija et al. (2004), o solo era Latossolo vermelho eutroférrico com microestrutura física semelhante em comportamento físico a solos arenosos, o que permite maior mobilidade de fitonematoides.

Com relação ao efeito da distância sobre a população de fitonematoides, verificou-se decréscimo da população de $M$. javanica de acordo com o aumento da distância do pseudocaule (Figura 1). A população de $H$. multicinctus foi maior a $40 \mathrm{~cm}$ de distância do pseudocaule $(\mathrm{P}<0,05)$ (Tabela 2$)$. Não houve ajuste de modelos de regressão para $H$. multicinctus. Araya et al. (1999) avaliaram a distribuição horizontal de fitonematoides em raízes de bananeira (Musa AAA cv. Valery), em solo argiloarenoso, na Costa Rica. Os autores verificaram que a população total de nematoides (Meloidogyne spp., Radopholus similis, Helicotylenchus spp. e Pratylenchus spp.) foi maior aos $30 \mathrm{~cm}$ de distância do pseudocaule. De acordo com Garcia (2000), o número de raízes, bem como o peso da massa fresca das raízes em banana Prata-Anã, é maior aos $5 \mathrm{~cm}$ do pseudocaule e tende a reduzir-se com a distância do pseudocaule. Não houve ajuste de modelos de regressão para $H$. multicinctus; no entanto, pelo teste de médias, observou-se maior população na distância de $40 \mathrm{~cm}$ (Tabela 2). Strich-Harari et al. (1966) encontraram maior quantidade de $H$. multicinctus na distância de $30-50 \mathrm{~cm}$ das raízes primárias a partir do pseudocaule. De acordo com Garcia (2000), elevada quantidade de raízes ativas para absorção de nutrientes é encontrada até um raio médio de $0,70 \mathrm{~m}$ a partir do pseudocaule.

A flutuação populacional de $M$. javanica, de dezembro de 2002 a novembro de 2004, nas diferentes profundidades e distâncias, foi independente da distância avaliada. A população média de M. javanica, na profundidade de $20 \mathrm{~cm}$, foi maior no mês de dezembro de 2002, com 486 J2/100 cc de solo, e reduziu-se a partir daí, estabilizando-se a partir de maio de 2004, com menor densidade populacional em julho de 2004 (74 J2) (Figuras 2A e 3A ). Comportamento semelhante ocorreu com a flutuação populacional de H. multicinctus (Figuras 2B e 3B). Isto pode ter ocorrido em função da alta precipitação em dezembro de 2002 (334 mm) e ausência de chuva no mês de julho de 2004 (Figura 4). Comportamento semelhante foi verificado nas demais profundidades avaliadas e na flutuação populacional nas raízes (Figura 5). É importante salientar que, durante as avaliações ao microscópio, observaram-se, a partir do mês de julho, vários nematoides parasitados por fungos. Isto, provavelmente, pode ter ocorrido em virtude da interrupção na aplicação de nematicidas que, anteriormente à implantação do experimento, era uma prática rotineira e poderia estar afetando a microbiota antagonista de nematoides (Gomes, 1996). De acordo com Jordan \& Mitkowski (2006), a suspensão do controle químico pode levar à estabilização da população de nematoides ao longo do tempo.

A densidade populacional de $M$. javanica variou de 26 juvenis/100g de raízes em dezembro de 2004 a 4.974 espécimes/100g de raízes em março de 2003. Já a população de $H$. multicinctus foi mais alta nos meses de dezembro de 2002 e março de 2003, com 9.028 e 6.946 espécimes $/ 100 \mathrm{~g}$ de raízes, respectivamente. (Figura 5). Por meio da análise de correlação de Pearson, não se verificou efeito significativo das variáveis climáticas: temperatura 
média mensal do ar, temperatura média máxima mensal do ar, temperatura média mínima mensal, umidade relativa média mensal e precipitação total mensal sobre a dinâmica populacional de $M$. javanica e $H$. multicinctus, pelo teste $t$ (dados não apresentados). A ausência de correlação entre as temperaturas e a dinâmica populacional, provavelmente, deveu-se à baixa variação das variáveis climáticas avaliadas. A variação da temperatura média mensal do ar, no período avaliado, foi de $23,4-27,6^{\circ} \mathrm{C}$ (Figura 6) e da umidade relativa foi de $37,3 \%$ no mês de setembro de 2004 a 72,3\% no mês de janeiro de 2004 (Figura 4). Araya et al. (2002) verificaram também pequena variação na população de vários nematoides em bananeira e atribuíram o fato à baixa variação na temperatura. A precipitação variou de zero, nos meses de maio, julho e setembro de 2004, a $337 \mathrm{~mm}$ em dezembro de 2002 (Figura 4). No entanto, tal variação, provavelmente, não se correlacionou com a dinâmica populacional, visto que, nos municípios do norte de
Minas, durante as épocas em que não ocorrem chuvas, os bananais são irrigados, não ocorrendo déficit de água para a planta. Resultados variáveis têm sido obtidos em estudos que correlacionam o número de dias de chuva com a população de nematoides. Na Jamaica, Hutton (1978) encontrou correlação negativa significativa entre a população de $H$. multicinctus do solo e o número de dias de chuva, e negativa com a população nas raízes. Já na Flórida, MacSorley \& Parrado (1981) encontraram correlação positiva entre tais variáveis. Quénéherve (1989), avaliando a dinâmica de nematoides em bananeiras cultivadas em solo mineral na Costa do Marfim, verificou correlação positiva entre a população de $H$. multicinctus e a precipitação em um sítio, porém em outro local não houve correlação. De acordo com este autor, a variação de tais resultados pode ser atribuída a diferenças no tipo e na temperatura do solo.

TABELA 1- Número médio de juvenis de segundo estádio (J2) de Meloidogyne javanica e de espécimes de Helicotylenchus multicinctus por $100 \mathrm{cc}$ de solo, nas profundidades de 20; 40 e $60 \mathrm{~cm}$, no perfil de solo cultivado com bananeira Prata-Anã irrigada, no norte de Minas Gerais, no período de dezembro de 2002 a novembro de 2004.

\begin{tabular}{lll}
\hline Profundidade $(\mathrm{cm})$ & $\begin{array}{l}\text { Meloidogyne } \\
\text { javanica }\end{array}$ & $\begin{array}{l}\text { Helicotylenchus } \\
\text { multicinctus }\end{array}$ \\
\hline 20 & $183,05 \mathrm{a}^{*}$ & $93,20 \mathrm{a}$ \\
40 & $167,17 \mathrm{a}$ & $64,60 \mathrm{~b}$ \\
60 & $103,70 \mathrm{~b}$ & $40,60 \mathrm{c}$ \\
\hline $\mathrm{CV}(\%)$ & 27,38 & 21,43 \\
\hline
\end{tabular}

* Médias seguidas pela mesma letra, nas colunas, não diferem significativamente entre si, pelo teste Scott-Knott, a 5\%.

TABELA 2- Número médio de espécimes de Helicotylenchus multicinctus por 100 cc de solo, nas distâncias de 20; 40; 80 e 120 cm do pseudocaule de bananeira Prata-Anã irrigada, no norte de Minas Gerais, no período de dezembro de 2002 a novembro de 2004.

\begin{tabular}{lc}
\hline Distância $(\mathrm{cm})$ & Helicotylenchus multicinctus \\
\hline 40 & $79,30 \mathrm{a}^{*}$ \\
20 & $65,93 \mathrm{~b}$ \\
80 & $64,27 \mathrm{~b}$ \\
120 & $61,30 \mathrm{~b}$ \\
\hline $\mathrm{CV}(\%)$ & 21,43 \\
\hline
\end{tabular}

* Médias seguidas pela mesma letra, nas colunas, não diferem significativamente entre si, pelo teste Scott-Knott, a 5\% 


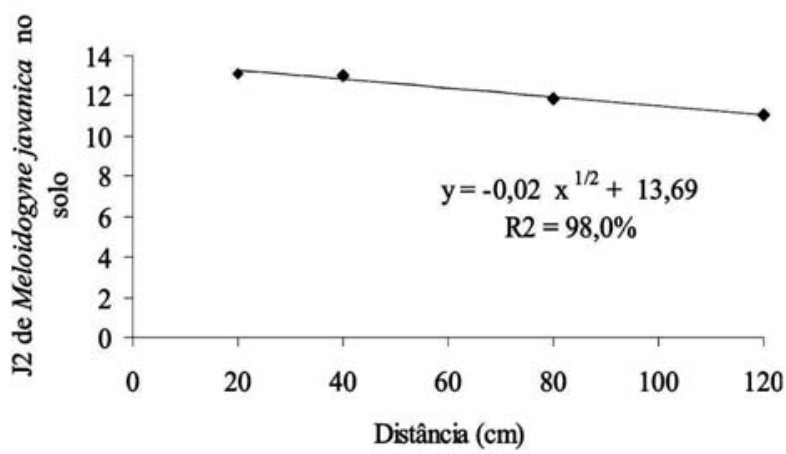

FIGURA 1- Número médio de juvenis de segundo estádio (J2) de Meloidogyne javanica, nas distâncias de 20; 40; 80 e $120 \mathrm{~cm}$ do pseudocaule de bananeira Prata-Anã irrigada, no norte de Minas Gerais, no período de dezembro de 2002 a novembro de 2004.
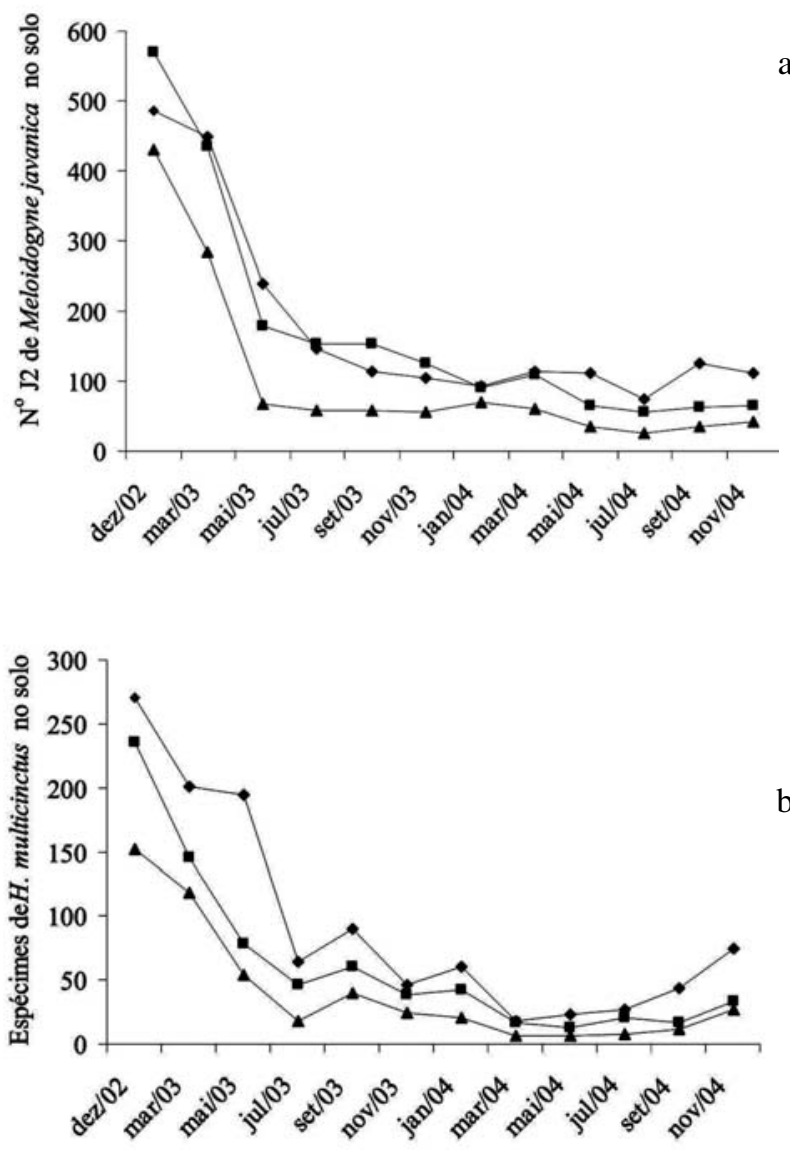

FIGURA 2- Número médio de juvenis de segundo estádio (J2) de Meloidogyne javanica (a) e espécimes de Helicotylenchus multicinctus (b), nas profundidades de 20 (४), 40 (\) e $60 \mathrm{~cm}(\mathbf{( )})$, no perfil do solo cultivado com bananeira Prata-Anã, ao longo de dois anos. 

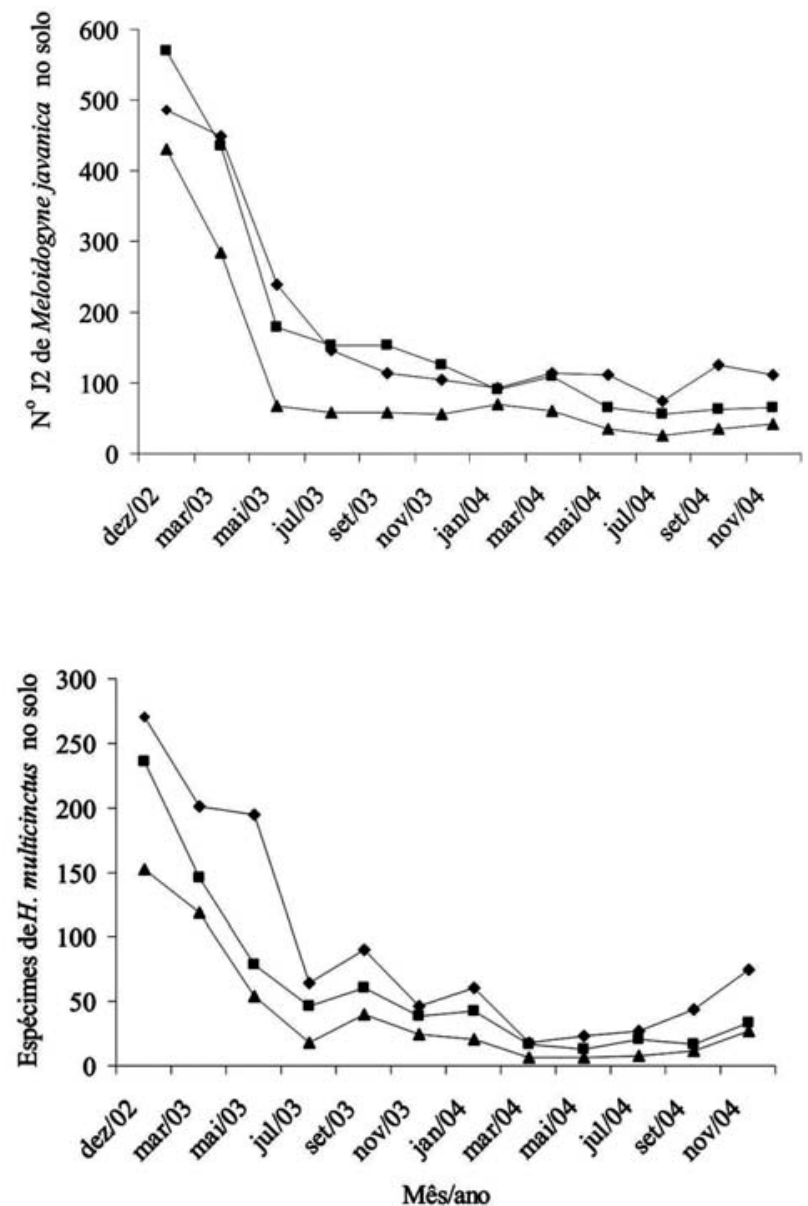

FIGURA 3- Número médio de juvenis de segundo estádio (J2) de Meloidogyne javanica (a) e espécimes de Helicotylenchus multicinctus (b) no solo, a $20(\bullet), 40(\mathbf{\bullet}), 80(\mathbf{\Delta})$ e $120 \mathrm{~cm}(\bullet)$ do pseudocaule de bananeira Prata-Anã, ao longo de dois anos.

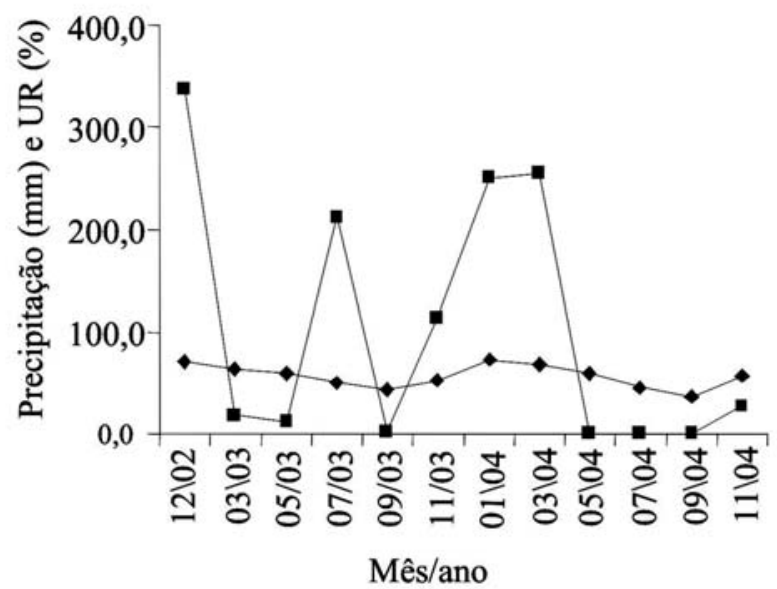

FIGURA 4- Umidade relativa média mensal ( ) precipitação mensal total (ロ) durante dois anos. 


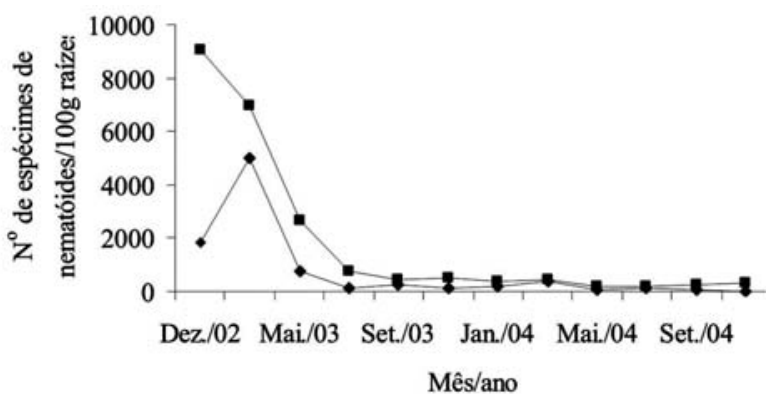

FIGURA 5- Densidade populacional de Meloidogyne javanica ( ) e Helicotylenchus multicinctus

(-) em raízes a $30 \mathrm{~cm}$ de distância do pseudocaule de bananeira, a $20 \mathrm{~cm}$ de profundidade, ao longo de dois anos.

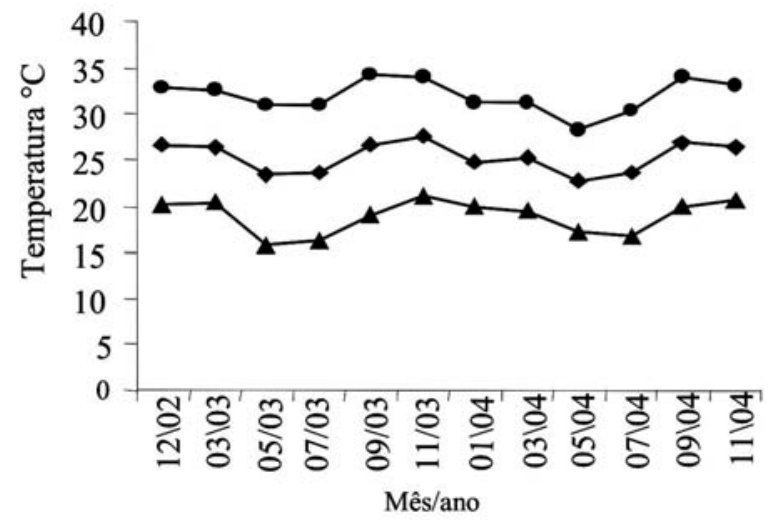

FIGURA 6 - Temperatura média mensal do ar $(\bullet$ ), temperatura média máxima mensal do ar $(\bullet)$ e temperatura média mínima mensal do ar ( $\boldsymbol{\Lambda})$, durante dois anos.

\section{CONCLUSÕES}

1- Maior abundância de Meloidogyne javanica e Helicotylenchus multicinctus ocorre na profundidade de $20 \mathrm{~cm}$.

2- O número de juvenis de segundo estádio de Meloidogyne javanica é maior a $20 \mathrm{~cm}$ de distância do pseudocaule da bananeira Prata-Anã.

3-Maior número de espécimes de Helicotylenchus multicinctus é encontrado a $40 \mathrm{~cm}$ de distância do pseudocaule da bananeira Prata-Anã.

4-A partir de março de 2003, as populações de Meloidogyne javanica e Helicotylenchus multicinctus decrescem e estabilizam-se.

\section{AGRADECIMENTOS}

Ao Conselho de Desenvolvimento Científico e Tecnológico (CNPq), pelo financiamento do projeto, e à Fundação de Amparo à Pesquisa do Estado de Minas Gerais (FAPEMIG), pela concessão de bolsa de Incentivo à Pesquisa e ao Desenvolvimento Tecnológico.

\section{REFERÊNCIAS}

AGRIANUAL 2005: anuário da agricultura brasileira. São Paulo: FNP Consultoria \& Agroinformativos, 2005. p. 221-229.

ALMEIDA, V. F.; CAMPOS, V. P.; LIMA, R. D. Flutuação populacional de Meloidogyne exigua na rizosfera do cafeeiro. Nematologia Brasileira, Brasília, v.11, p.159-175, 1987.

ARAYA, M.; VARGAS, A.; CHEVES, A. Nematode distribution in roots of banana (Musa AAAcv. Valery) in relation to plant height, distance from the pseudostem and soil depth. Nematology, Leiden, v.1, n.7, p.711-716, 1999.

ARAYA, M.; DE WAELE, D.; VARGAS, R. Occurrence and population densities of nematode parasites of banana (Musa spp.) roots in Costa Rica. Nematropica, Alburn, v.2, n.1, p.21-33, 2002.

BIRD, G. W.; RAMSDELL D. C. Population trends 
and vertical distribution of plant-parasitic nematodes associated with Vitis labrusca L. in Michigan. Journal of Nematology, Marceline, v.17, p.100-107, 1985.

CARNEIRO, R. M. D. G.; CARNEIRO, R. G.; MONTEIRO, A. R. Distribuição vertical de quatro espécies de nematoides parasitas de cana-de-açúcar em relação a certas propriedades do solo. In: REUNIÃO BRASILEIRA DE NEMATOLOGIA, 6 , 1982, Fortaleza. p.117-32.

COSTA, D. C. C.; SILVA, S. O.; ALVES, F. R.; SANTOS, A. C. Avaliação de danos e perdas à bananeira cv. Nanica causadas por Meloidogyne incognita na região de Petrolândia-PE. Nematologia Brasileira, Brasília, v.21, n.1, p.21, 1997.

COOLEN, W. A.; D'HERDE, C. J. D. A method for the quantitative extraction of nematodes from plant tissue culture. Ghent: State Agriculture Research Centre, 1972.77p.

DAVIS, R. F.; WILKINSON, H. T.; NOEL, G. R. Vertical distribution of three nematode genera in a bentgrass putting green in Central Illinois. Journal of Nematology, Marceline, v.26, n.4, p.518-521, 1994.

DIAS, M. S. C., SILVA, M. S.; LOPES, T. C.; RIBEIRO JUNIOR, P. M.. Ocorrência de nematoides associados a bananeira na região norte de Minas Gerais. Fitopatologia Brasileira, Brasília, v.26, p.499-500, 2001.

FERRAZ, L. C. C. B. Radopholus similis em banana no Brasil: considerações gerais sobre o problema com ênfase aos danos causados à cultura. In: CONGRESSO INTERNACIONAL DE NEMATOLOGIA TROPICAL; CONGRESSO DA SOCIEDADE BRASILEIRA DE NEMATOLOGIA, 19., CONGRESSO DA ORGANIZAÇÃO DOS NEMATOLOGISTAS DAAMÉRICATROPICAL, 27., 1995, Rio Quente. Anais... Piracicaba: Sociedade Brasileira de Nematologistas, 1995. p.176-185.

FORTUNER, R. The Hoplolaiminae. In: NICKLE, W. R. (ed.). Manual of agricultural nematology. New York: Marcel Dekker, 1991. p.669-719.

GARCIA, R.V. Sistema radicular de bananeira irrigada por aspersão convencional e microaspersão no Projeto Jaíba-MG. 2000. 47 f. (Dissertação de Mestrado) - Universidade Federal de Viçosa, Viçosa, 2000.
GONZAGA, V. Nematoides associados a bananeiras na região norte de Minas Gerais. Fitopatologia Brasileira, Brasília, v.22, p.326, 1997. Suplemento

GOMES, J. T. Dispersion and level of root infestation by the "burrowing nematodes Radopholus similis." Cobb in some banana plantations of El Oro province, Ecuador. In ACORBAT Meeting. 12, 1996, Santo Domingo. Abstract... Santo Domingo: Junta Agroempresarial Dominicana, 1996. p. 88.

HARTMAN, K. M.; SASSER, J. N. Identification of Meloidogyne species on basis of differential host test and perineal-pattern morphology. In: BARKER, K. R., CARTER, C.C.; SASSER, J. N. (Ed.). An advanced treatise on Meloidogyne. Raleigh, NC: University Graphics, 1985. v.2, p.525-543.

HUTTON, D. G. Influence of rainfall on some plantain nematodes in Jamaica. Nematropica, Alburn, v.8, p.34-39, 1978.

JENKINS, W. R. A rapid centrifugal-flotation technique for separating nematodes from soil. Plant Disease Reporter, Beltsville, v.48, n.9, p.692. 1964.

JORDAN, K. S.; MITKOWSKI, N. A. Population dynamics of plant-parasitic nematodes in golf course greens turf in Southern New England. Plant Disease, St. Paul, v.90, n.4, p.501-505, 2006.

KASHAIJA, I. N.; MCINTYRE, B. D.; SSALI, H.; KIZITO, F.. Spatial distribution of roots, nematode populations and root necrosis in highland banana in Uganda. Nematology, Leiden, v.6, n.1, p.7-12, 2004.

LAUGHLIN, C. W.; LORDELLO, L. G. E. Sistemas de manejo de nematoides: relações entre a densidade de população e os danos à planta. Nematologia Brasileira, Piracicaba, v.2, p.15-24, 1977.

MACGUIDWIN, A. E. Abundance and vertical distribution of Longidorus breviannulatus associated with corn and potato. Journal of Nematology, Marceline, v. 23, p.73-81, 1977.

MACSORLEY, R.; PARRADO J. L. Population fluctuations of plant-parasitic nematodes on bananas in Florida. Proceedings of the Florida State Horticultural Society, Florida, v.94. p.321-323, 1981.

NAGY, P.; BAKONYI, G.; JENSER, G. Observations on the vertical distribution of Xiphinema vuittenezi (Longidoridae, Nematoda) in an apricot orchard in 
Hungary. Nematologia Mediterrânea, Bari, v.26, p.267-270, 1998.

PORTAL DA FRUTICUltura. Portal da Fruticultura no norte de Minas: informações de mercado. Disponível em: <http:/ www.abanorte.com.br/mercado $>$. Acesso em: 10 abr. 2007.

QUÉNÉHERVE, P. Population of nematodes in soils under banana, cv. Poyo, in the Ivory Coasy. 3. Seasonal dynamics of populations in mineral soil. Revue Nematolologie, Montrouge, v.12, n.2, p.149160. 1989.
STRICH-HARARI, D.; MINZ, G.; PELED, A. The spread of spiral nematodes in banana roots and their control. Israel Journal of Agricultural Research, Rehovot, v.16, p.89-94, 1966.

TSENG, S. T.; ALLRED, K. R.; GRIFFIN, G. D. A soil population study and Ditylenchus dipsaci (Khun) Filipjevin and alfafa field. Proceedings of the Helminthological Society of Washington, Beltsville, v.35, p.57-62, 1968.

WINDHAM, G.L.; BARKER, K. R. Spatial and temporal interactions of Meloidogyne incognita and soybean. Journal of Nematology, Marceline, v.25, n.4S, p. 738-745, 1993. 